it will be extremely useful to students and lecturers in palaeontology, geology, zoology and general biology, and is a 'must' for researchers in the field.

Philippe Janvier is at the CNRS, Laboratoire de Paléontologie, Museum National d'Histoire Naturelle, 75005 Paris, France.

\section{Call}

\section{of the wild}

\section{Signalers and Receivers: \\ Mechanisms and Evolution of Arthropod Communication by Michael D. Greenfield \\ Oxford University Press: 2002. 426 pp. \\ $\mathfrak{E} 62.50, \$ 80$}

\section{Ron Hoy}

Communication between members of one's own kind is one of the most important behavioural acts that any animal must perform well if its genes are to be represented in the next generation. An alpha male (of any ilk) who has gained his 'top dog' advantage by virtue of his competitive prowess has fought for nought if his actions don't translate eventually into puppies of similar ilk.

This little book is ostensibly about how arthropods, but mainly insects, produce and consume signals in the behavioural commerce of competition and courtship. The evolutionary issues at stake, following Darwin, are neatly divided into the primary sensory modalities of sound, smell, sight and touch, and could as well be applied to fish, frogs, birds or mammals (and, if we follow the evolutionary psychologists, humans).

The book's subtitle pays homage to the fact that the diverse and numerous arthropods - most prominently, insects and spiders by land, and crabs and lobsters by sea - have some of the most varied modes of communication in the animal kingdom. Every possible sensory modality known (and some particular only to them) is exploited by arthropods for transmitting and receiving communication and signals. As a consequence, the topic of arthropod communication has generated a huge literature, and the book lists 71 pages of references, making it a valuable resource for this alone. The text itself is just 295 pages, but Michael Greenfield has done a thoughtful, excellent job of highlighting the central theoretical issues and selecting salient examples from this huge literature.

The chemical senses, smell and taste, are extremely important in arthropods and, depending on the species, mediate everything from finding food to finding a mate. Through hormonal actions they also mediate developmental decisions. The chemical senses seem to be crucial links in the behav- ioural networks that enable the evolution of hierarchically complex societies of individuals. Greenfield discusses the behavioural and evolutionary aspects of olfaction admirably, primarily within the context of sexual advertisement and courtship, especially in moths, where much of the work has been done.

But in his coverage of moths, I wish that he had delved more deeply into the mechanistic aspects of communication, particularly its physiology and biochemistry, where so much excellent work has been done over the past 30 years. Thanks to work in selected model systems, such as the tobacco hornworm moth (Manduca sexta), we know a lot about molecular receptor systems, especially the neural systems that underlie developmental systems and courtship behaviour, which make up the neuroethology of communication. On the other hand, the virtues of this book are its conciseness and clear writing, so I suppose the author had to be selective about what to include.

The lion's share of attention is given to the chapter on mechanical signals, sound and vibration, which are the focus of the author's own research. From a comparative point of view, acoustic signalling is the province of only two groups of animals, the arthropods and the chordates. Greenfield devotes much of his narrative to the remarkably diverse ways and means by which insects produce and receive acoustic signals. Insects produce signals by rubbing body parts together (stridulation), substrate vibration, tymbal mechanisms (in cicadas) and hissing; all are described, primarily in narrative form.

Here there appears to be a lost opportunity in the author's book plan. Although the book contains some excellent diagrams and other pictorial material, it could have done with at least twice as many depictions of mechanisms and even pictures of the animals themselves. Most of the illustrations are drawings, which is fortunate because the photographs are poorly reproduced. I was also surprised to see how little the author devotes to acoustic communication in the fruitfly Drosophila, given the status of $D$. melanogaster as a model organism, especially for behavioural-genetics studies.

The chapter on vision is the shortest but provides a sketchy outline on central issues of visual communication. Perhaps Greenfield was aware that the subject of arthropod vision has been masterfully covered in a recent book on the subject by Michael Land, Animal Eyes (Oxford University Press, 2001).

Signalers and Receivers concludes with a chapter on sexual selection and the evolution of signals, which is appropriate because insects have always been a rich source of insight into these topics. It is perhaps no accident that some of the major modern thinkers in evolutionary behaviour theory

\title{
Insects in focus
}

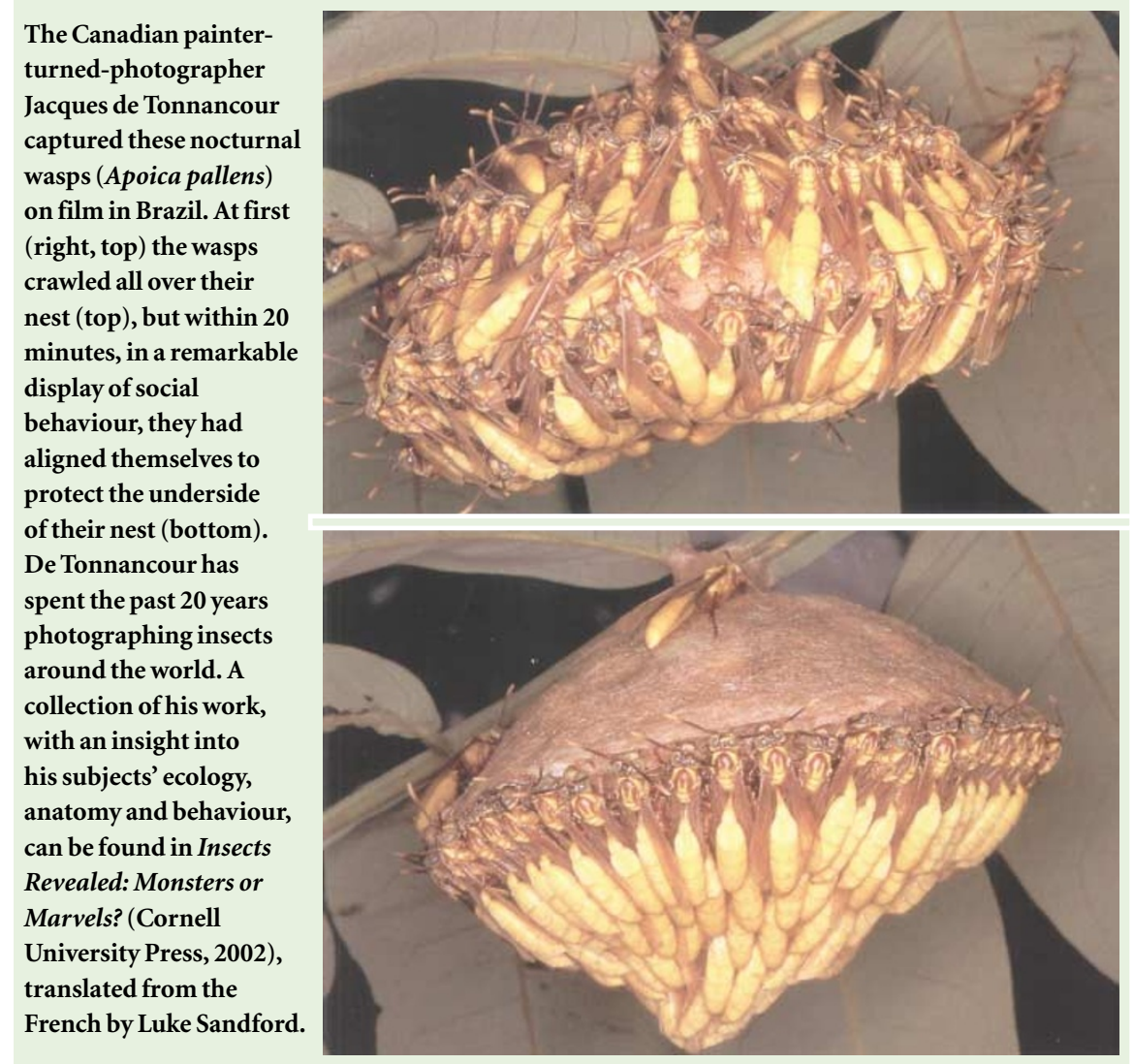


were themselves entomologists, including W. D. Hamilton, R. D. Alexander and E. O. Wilson - so too was Alfred Kinsey, but that's another story. However, the five pages devoted to this chapter are so sketchy that I was left disappointed because insect studies have so much to bring to the general discussion. However, evolutionary issues arise and are discussed throughout the book.

In summary, this is a valuable addition to the literature on animal communication at an introductory level. Greenfield's book is worthwhile precisely because it is brief. I will recommend this book for undergraduate courses and for the generalist reader who wants to know more about this interesting subject. Advanced readers would also enjoy reading the book but may find it wanting for depth and detail, although they will greatly appreciate the reference list.

Ron Hoy is in the Department of Neurobiology

and Behaviour, Cornell University, Ithaca,

New York 14853, USA.

\section{Journey to the stars}

\author{
Children of the Stars: Our Origin, \\ Evolution and Destiny \\ by Daniel R. Altschuler \\ Cambridge University Press: 2002. 280 pp. \\ $\mathfrak{1} 19.95, \$ 28$
}

Disturbing the Solar System:

Impacts, Close Encounters, and

Coming Attractions

by Alan E. Rubin

Princeton University Press: 2002. 376 pp.

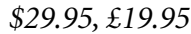

\section{Charles A. Wood}

Astronomy is the most awe-inspiring science. It seeks to understand the Universe: all time and matter, inconceivable distances, and ultimate questions of beginnings and endings, of life and existence. Generations of astronomers have written books to share the excitement of discoveries with the public, and the visually and scientifically stunning images from the Hubble Space Telescope and planetary exploration have generated a large number of recent popular books.

Scientists writing for the public have the difficult challenge of carefully explaining science yet maintaining a writing style that captivates lay readers. Children of the Stars and Disturbing the Solar System come close, but fall on either side of the ideal. They both range further than the Solar System, but this, as the human home, is their focus.

The perspective of Children of the Stars is spelled out by the title and subtitle. It is the now-familiar tale that humans are derived from stardust - a retelling and updating of popular books by George Gamow, Carl

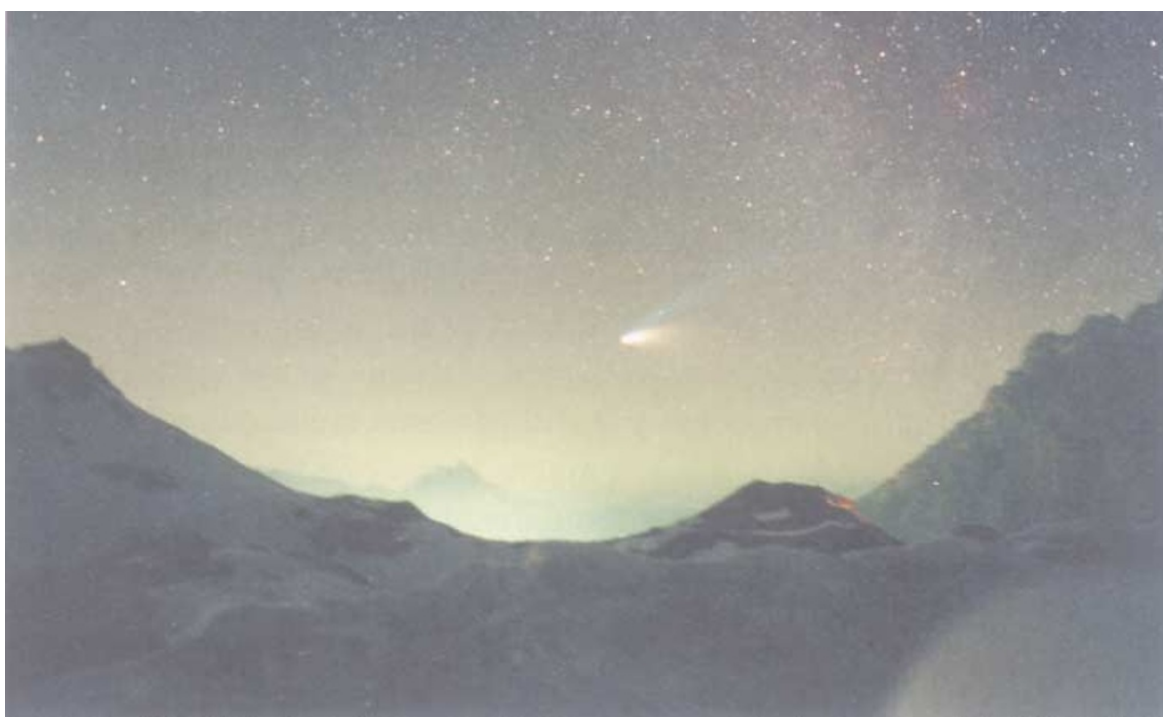

Starstruck? Events such as the appearance of Comet Hale-Bopp fuel the public's interest in astronomy.

Sagan and others. Daniel R. Altschuler covers a lot of territory, including the size and structure of the Galaxy, how the Sun works, dying stars as creators of heavy elements, planetary formation, the geology of the Earth, the origin and working of life, giant impacts, and the human despoilation of our planet.

Altschuler brings a passion and attitude to his writing that makes Children of the Stars lively and personal. He delights in fascinating factoids (our brain contains as many neurons as there are stars in the Galaxy; there are more bacteria in your gut than there are humans on Earth), and provides humorous comments. Following his statement that some bacteria live happily in a polluted river, he adds: "Well, I have not actually asked them if they are happy." There is also a romantic speculativeness - for example, the 28-day human menstrual cycle may date from 500 million years ago when "biological clocks first might have been set in primitive living things" - that may make the reader question the scientific foundation of other statements.

Disturbing the Solar System is a very different book that covers many of the same topics. Whereas Altschuler often devotes only a paragraph or two to a subject, Rubin commonly provides a fuller history, including failures of understanding along the way. Most of the chapters are modest revisions of articles previously published in the Griffith Observer and other popular astronomy magazines. Each chapter ends with an obviously tacked-on transition paragraph to the next. The chapters have a well-defined focus, but also sometimes a pedantic completeness - such as listing all the moons of a planet — that fails to add to the story. Unlike Altschuler, Rubin is nearly invisible as an author: the word "I" occurs infrequently. The book is scientifically accurate, and the writing is quietly competent.

Rubin cannot be accused of merely focusing on trendy, exciting topics. Nearly half of his chapters represent his research interests in meteorites, asteroids and impact cratering, which are important but not yet over-told tales. Two chapters on the Galaxy and ice ages seem out of place here. The book ends with the now de rigueur chapters on astrobiology, including a fascinating look at how humans might react if aliens were detected.

The books' dust-jackets suggest that these two books are aimed at the same generalpublic audience, but the books are quite different. Altschuler provides some thoughtprovoking one-liner titbits, while Rubin offers more thorough explanations. The level of science in Altschuler's book is similar to my son's eighth-grade textbooks, whereas Rubin's book approaches an introductory college text. Altschuler's book is a fun read, perhaps a transcript of well-received lectures he gives to the public; Rubin's volume could be used as a reference. The look and feel of the books reflect their writing styles. Most two-page spreads in Altschuler's book contain a colour photo (unfortunately with difficult-to-read blue captions), whereas Rubin's contains a much more limited number of mostly older, black-and-white photos, graphs and diagrams.

The science section of my local public library is overrun with glossy new books that sensationalize or water down science, throw-away volumes that end up a year or two later on the library sale tables. These two books rise above that level. Altschuler's Children of the Stars would be a good gift to excite anyone - nieces, nephews, parents and professionals in other fields - about the wondrous connections between humans and the cosmos. And for those who want more meat, Rubin's Disturbing the Solar System is hearty fare.

Charles A. Wood is at Biosphere 2, Columbia

University, Oracle, Arizona 85623, USA. 